Erótica e semiótica decadentista: uma leitura de A confissão de Lúcio, de Mário de Sá-Carneiro. Rafael Santana Gomes (Dissertação de Mestrado em Literatura Portuguesa. Faculdade de Letras - UFRJ, 2010. Orientadora: Teresa Cristina Cerdeira da Silva.)

\title{
NA CLAVE DO DECADENTISMO PORTUGUÊS
}

Fundado, em 1915, pela "Geração Orpheu", o Modernismo português ocupa, na cena da literatura universal, lugar especial, sobretudo pela figura ímpar de Fernando Pessoa (1888-1935), que se "outrou" em tantos que o "baú", por seu imprevisível acervo, não cessa de fascinar. Ao lado do poeta de Mensagem (1934), inscreve-se outro nome, quase um seu irmão-gêmeo - Mário de Sá-Carneiro (1890-1916) -, que, embora não goze, como Pessoa, de uma fabulosa fortuna crítica, tem, também, uma produção, em prosa, em drama, em epistolografia e em poesia, tão polissêmica que não deixa de entusiasmar a quantos de sua obra tenham o privilégio de se achegarem. Tributário, como Álvaro de Campos - heterônimo pessoano -, do futurismo, que promoveu em seu país, Mário de Sá-Carneiro teceu, febrilmente, o elogio do cosmopolitismo e da civilização mecânica, a ponto de tomar emprestado às técnicas publicitárias os slogans e o grafismo, como fica mais que patente no poema "Manucure", publicado, em junho de 1915, no segundo e último número da revista Orpheu, de que extraímos este paradigmático fragmento: "E eu sempre na sensação de polir as minhas unhas / E de as pintar com um verniz parisiense, / Vou-me mais e mais enternecendo / Até chorar por Mim... / Mil cores no Ar, mil vibrações latejantes, / Brumosos planos desviados / Abatendo flechas, listas volúveis, discos flexíveis, / Chegam tenuamente a perfilar-me / Toda a ternura que eu pudera ter vivido, / Toda a grandeza que eu pudera ter sentido, / Todos os cenários que entretanto Fui... / Eis como, pouco a pouco, se me foca / A obsessão débil dum sorriso / Que espelhos vagos reflectiram...”. No primeiro número da revista Orpheu, publicado em março de 1915, Fernando Pessoa apresentou o decadentista poema "Opiário", justamente dedicado "Ao Senhor Mário de Sá-Carneiro", onde se lê esta alucinante estrofe inaugural: "É antes do ópio que a minh'alma é doente. / Sentir a vida convalesce e estiola / E eu vou buscar ao ópio que consola / Um Oriente ao oriente do Oriente". 
O conjunto da obra do poeta de Dispersão (1914), fruto macerado de uma extremada sensibilidade, marca-se, em princípio, pelo simbolismo, vinca-se das vanguardas aureorais do século $\mathrm{XX}$ - Futurismo, Surrealismo, Interseccionismo, Sensacionismo, Dadaísmo e Paulismo - e vai, definitivamente, na direção, tortuosa e torturante, do decadentismo finissecular, tornando-se cada vez mais complexa e culminando na dispersão total e no aniquilamento do "eu", porque perdido no "labirinto de si próprio".

No estudo do modernismo português, faltava um estudo circunscrito ao decadentismo, de que Sá-Carneiro é prócer incontestável, na medida em que seus escritos, incluindo sua correspondência, de 1912 a 1916, com Fernando Pessoa, e com o decadentista Luís de Montalvor (1891-1947), também membro do "Grupo Orpheu", transgridem, escandalosamente, o código vigente em Portugal, colocando-se sob a clave da estética decadentista, nascida na França fin-de-siècle com a narrativa evanescente de Joris-Karl Huysmans (1848-1907), criador de des Esseintes, protagonista agônico do romance $\grave{A}$ rebours (1884). Herdeira direta, ou melhor, filha bastarda de $A$ rebours, entroniza-se esta trilogia perversa: o romance-paradigma do decadentismo inglês - The picture of Dorian Gray (1890), do irlandês Oscar Wilde (1854-1900), o romance-emblema do decadentismo italiano - Il piacere (1889), de Gabriele D'Annunzio (1863-1938) e, last, but not the least, A confissão de Lúcio (1914), de Sá-Carneiro. A dissertação de mestrado em Literatura Portuguesa, de Rafael Santana Gomes, defendida em 23 de fevereiro de 2010, na UFRJ, toma, precisamente, como corpus, esse romance sá-carneiriano, investigado acuradamente - e, aqui, o significante "investigado" reassumiria, ao lado de sua significação patente de análise acadêmica, quase um sentido literal, na medida mesma em que $A$ confissáo de Lúcio poderia ser lida sob o prisma de um romance policial à la Edgar Allan Poe (1809-1849), por exemplo. $\mathrm{O}$ autor da dissertação investiga, ao longo de 139 páginas, a natureza, até então, pouco ou nada explorada, decadentista, não apenas da narrativa em pauta quanto do próprio Decadentismo à la portuguesa, que prefacia o modernismo em Portugal; aliás, o mestre em Literatura Portuguesa assinala, logo no início de seu estudo, que "a questão do Decadentismo encontra-se, em relação aos estudos específicos do Modernismo português, um tanto relegada a segundo plano, porque entendida tão-somente como uma espécie de culto ao passado". Assevera o mestre em Literatura Por- 
tuguesa: "Dentre os muitos aspectos nos quais a estética decadentista prefacia a modernidade, encontramos, no bojo de seus postulados, a própria ideia de fragmentação do sujeito, desenvolvida a partir da temática do duplo". Eis, pois, lançado o desafio, que a dissertação enfrenta, tomando como alvo o romance $A$ confissão de Lúcio, tornado "bíblia" profana da estética decadentista em Portugal. Vazado numa real écriture artiste ou écriture-dandy, o texto de Rafael Santana espelha, agora no cânone ensaístico, o próprio texto analisado, configurando, destarte, uma crítica artística. Ouvem-se ressonâncias do aforismo barthesiano, inscrito na aula com que inaugurou, no Collège de France, em 7 de janeiro de 1977, a cadeira de semiologia literária: "Le texte que vous écrivez doit me donner la preuve qu'il me désire. Cette preuve existe: c'est l'écriture". Aponte-se, verbi gratia, o tratamento parafrástico desconstrutor de um sintagma de sua orientadora pelo orientando: Teresa Cerdeira escreveu "no tapete das certezas"; Rafael Santana releu: "no tapete onírico das incertezas", "no fio onírico das incertezas". Orientadora e orientando remetem a Oscar Wilde que, em $O$ retrato de Dorian Gray, faz o narrador declarar um sonho seu: "I should like to write a novel certainly, a novel that would be as lovely as a Persian carpet and as unreal". Nos três estudiosos do Decadentismo - Oscar Wilde, o irlandês, Teresa Cerdeira, a niteroiense, Rafael Santana, o saquaremense - a metáfora do tapete figura, en beauté, o texto da irrealidade da mimesis.

Rafael Santana postula, então, que "a narrativa decadentista, 'espaço fantasmático do sujeito', apresenta, propositadamente, em seu próprio tecido discursivo, os jogos estruturais, o simulacro, a inversão da mimesis, a crise da verdade, a crise da memória, os sonhos, os delírios, os estilhaços dos fatos, a comunhão com a poesia e a consciência textual da escritura, ao se impor não mais como representação da realidade, mas sim como máscara, tessitura, teatralização, jogo de linguagem". Com tal sistema de signos à deriva, a estética decadentista revela-se totalmente iconoclasta e inaugura algo de absolutamente novo - le nouveau à tout prix, gritavam os Decadentes -, que desemboca no burburinho dos signos modernistas.

A fim de analisar, meticulosa e agudamente, essa narrativa (às vezes denominada, na crítica literária, "novela" ou, até, "conto", denominações com as quais o autor da dissertação não concorda, embora não ache necessário patentear sua posição quanto à classificação do texto), Rafael Santana arma uma estrutura coesa e seduto- 
ra, que divide o estudo em três grandes partes, todas iniciadas por um arcabouço de estudo teórico: na "Parte I", nomeada "Ética e estética", estudam-se as "ressonâncias decadentistas no Modernismo português", através de Baudelaire, Gautier, Huysmans e Wilde, "tutores da modernidade", chegando-se a Sá-Carneiro e Pessoa, que se enveredam pelas "sendas do Decadentismo". A práxis, nessa parte inaugural, contempla $A$ confissão de Lúcio como "uma narrativa moderna”. Já a "Parte II", intitulada "Os mestres", inicia-se, como todas as partes da dissertação, com uma teorização sobre o romance de aprendizagem e se desenvolve lendo $A$ confissão de Lúcio, sob o signo da Esfinge e da Quimera, como "um ensino às avessas". Designada "Erótica e semiótica", a terceira parte trata da estética da artificialidade, do culto do dandismo, do duplo e da "festa decadentista", "uma orgia do fogo", em que esplende a voluptuosidade, sobretudo no seu viés homoerótico.

A partir do próprio título da dissertação, ficam patentes, não só o corpus de análise, como a estética estudada - o Decadentismo -, e a metodologia esposada, a semiologia de cariz barthesiano. Com efeito, será a semiologia - teoria geral dos signos -, baseada na linguística de Ferdinand de Saussure (1857-1913) e desenvolvida por Roland Barthes (1915-1980), a moldura teórica que levará ao escrutínio dos signos e à ação de descortinar os signos decadentistas incrustados em $A$ confissão de Lúcio. A semiologia literária barthesiana vem acompanhada de outros pensadores no campo da Teoria Literária, da Sociologia da Literatura, da crítica literária, da Poética, dos estudos culturais, enfim, que fazem com que se promova um seminal diálogo intertextual; travando "conversas d'alma" com autores, como, por exemplo - além dos citados Saussure e Barthes e de sua orientadora Teresa Cerdeira-, Anatol Rosenfeld, Antoine Compagnon, Bakhtin, Catherine Coquio, Eduardo Lourenço, Georges Bataille, Ian Watt, José Carlos Barcellos, José Carlos Seabra Pereira, Junito Brandão, Luiz Edmundo Bouças Coutinho, Lukács, Octavio Paz, Vítor Manuel de Aguiar e Silva, Yves Vadé, Rafael Santana urde todo um campo teórico que o leva a significações do texto par excellence do Decadentismo português. Esse profícuo diálogo intertextual não manifesta, de modo algum, uma relação de submissão, tampouco de arrogância com relação aos teóricos privilegiados; pelo contrário, Rafael Santana atua, como convém numa dissertação de mestrado, que busca a excelência, qual interlocutor que escolhe seus interlocutores, já consagrados pela crítica universal, e vai, pian 
piano, construindo uma visão outra, uma prismatização, uma dialética, em que sistemas de signos, em fricção, projetam estilhaços de significaçôes. Ao trazer à baila, por exemplo, a categoria do "dispêndio", segundo Bataille, o mestre-pesquisador carreia significaçốes para o campo da erótica decadentista.

Participante da banca de exame final, a Profa. Dra. Mônica Genelhu Fagundes pondera, valorizando a relação sempre presente entre "ética e estética" - mas vai além: "as formas subjetivas e o mundo social, o imaginário e a representação e a experiência histórica [...]. Isso se promete e se cumpre ao longo de toda a dissertação e nunca tratando a questão histórica como matéria temática da representação literária, mas como um conjunto complexo de fatores que interferem no modo, nos limites, na possibilidade (ou impossibilidade) de representação. Isso é importantíssimo ao se considerar o caso d'A confissão de Lúcio: estruturalmente irônica, a todo momento questionando a sua possibilidade. Confissão objetiva mas cheia de impressões, de incertezas, de contradições. Verdadeira mas inverossímil".

Com relação ao Decadentismo enquanto estética finissecular, esta dissertação dá conta, quase total, das referências bibliográficas e de sites da Internet, que abarcam o tema. Já no campo específico das referências, o trabalho em pauta representa uma imperdível contribuição aos estudos da Literatura, seja ela portuguesa ou de qualquer outra nacionalidade. No fundo e na superfície, são a teoria literária, a teoria do romance, a teoria crítica, a semiologia, que dão o tom da leitura e trazem contributos, que ultrapassam as exigências de uma dissertação comum, atingindo raias de tese de doutoramento. Não se trata, de fato, de uma tese, porque esse não era o conceito; no entanto, a dissertação aponta o doutorado e vislumbra horizontes de uma pesquisa em nível de doutoramento.

Co-fundador do Modernismo português, o cabo-verdiano Luís de Montalvor criou um aforismo, que se aplicaria, ipsis litteris, à vida-obra ou obra-vida de Mário de Sá-Carneiro: "A vida não vale pelo que é, mas pelo que dói... Só a Beleza nos interessa". Até ao suicídio doeu a vida a Sá-Carneiro que (re)criou, à maneira decadentista, a Beleza, com "B” maiúsculo. Por seu turno, Fernando Pessoa, outro membro da revista Orpheu, deixou consignadas estas consideraçôes, que definem, ou melhor, indefinem, o decadentismo à la Sá-Carneiro, espelho labiríntico, "vidente", "funâmbulo da gramática": "Temos a decadência proveniente da falência de 
todos os ideais passados e mesmo recentes. Temos a intensidade, a febre, a atividade turbulenta da vida moderna. Temos, finalmente, a riqueza inédita de emoções, de ideias, de febre e de delírio que a Hora europeia nos traz".

Investigando, vertical e abundantemente, o decadentismo português em $A$ confissão de Lúcio, onde se expõe um espelho calesdocópico das personagens, em que o narrador-autor se mira sob inúmeros ângulos, sem, todavia encontrar-se, antes dissolvendo-se no giro dos signos refletidos, Rafael Santana corrobora, com argumentos, contra-argumentos e beleza, o enunciado de Ernst Curtius (1886-1956), para quem "A sensibilidade decadente foi uma forma, historicamente explicável, da angústia moderna”. Lido na clave do Decadentismo, Sá-Carneiro epitoma o homem moderno, já in nuce no personagem decadentista, espelho caleidoscópico de sinestesias. No fundo do espelho narrativo de $A$ confissão de Lúcio, todas as cinco personagens (cinco pontas de uma mesma estrela decadente discursiva) - Gervásio Vila Nova, Lúcio, Ricardo Loureiro, a americana e Marta - são avatares avariados do narrador-autor ou autor-narrador, totalmente perdido e emaranhado no abismo textual.

No ano em que se celebram os 120 anos do nascimento de Sá-Carneiro, a dissertação de Rafael Santana significa uma homenagem apoteótica ao escritor de $A$ confissão de Lúcio, também ele "poeta das Brasas".

Latuf Isaias Mucci (UFF) 